\title{
Determining the vitality of urban centres
}

\author{
J. E. Drewes \& M. van Aswegen \\ North West University, Potchefstroom Campus, South Africa
}

\begin{abstract}
This paper will attempt to provide an encompassing Index of Vitality for urban centres. The Vitality Index's ${ }^{\mathcal{O}}$ goal is to enable measurement of the general economic, social, physical, environmental, institutional and spatial performance of towns within a regional framework, ultimately reflecting the spatial importance of the urban centre. Towns have been measured in terms of numerous indicators, mostly in connection with social and economic conditions, over an extended period of time. The lack of suitable spatial indicators is identified as a significant shortcoming in the measurement of urban centres. This paper proposes the utilisation of a comprehensive index to measure the importance of an urban centre within a specific region. The Vitality $\operatorname{Index}^{\mathcal{O}}$ is consequently tested in a study area situated in the Northern Cape Province, South Africa. This study contributes in a number of ways to the measurement of urban centres, i.e. the shortcomings that are identified for the urban centres can be addressed by goal-specific policy initiatives, comprising a set of objectives and strategies to correct imbalances. The Vitality Index ${ }^{\mathcal{O}}$ also provides a basis for guiding national and regional growth policies, in the identification of urban centres with sustainable growth potential and vitality.
\end{abstract}

Keywords: sustainability indicators, measuring urban centres, importance of urban centres, sustainable housing, spatial planning; policy, South Africa.

\section{Introduction}

Various indicators have been designed and are recognised to provide a quantitative evaluation of an urban centre. Included are indicators describing economic growth, accessibility, sustainability, quality of life and environmental quality. In Developing Countries, basic indicators like access to engineering services, employment levels and availability of public transport form the main 
urban evaluation indicators (DBSA [1]). In Developed Countries, on the other hand, indicators used to evaluate and describe cities focus more on standards of living, environmental quality and accessibility (Schneider [2]).

In the course of time these indicators have also progressed in terms of focus. In recent times, the focus has shifted towards qualitative issues like quality of living, although the main focus is still on economic growth and production. In the post-modern era, cities are generally analysed and evaluated by means of indicators reflecting sustainability, competitiveness, global impact and environmental quality. These are qualitative indicators.

Numerous technical and / or spatial planning indicators have also been compiled to aid in the spatial planning process (i.e. central place index, locality index, and income and labour indexes). These spatial planning indicators have not, however, been included in assessing the spatial importance and vitality of urban centres within a particular region. This disregard of spatial measures is emphasised by this study as a shortcoming in the measurement and assessment of urban centres within regions.

Most of the foregoing indicators refer to quantitative measurements. Arguably, several qualitative issues also need to be taken into consideration, e.g. the sense of community and sense of place linked to a certain urban structure. The quantitative indicators do not necessarily reflect the total of the unique social characteristics of a city (Liu [3]).

The main problem statement amounts to a lack of integrated and encompassing indicators that reflect on the urban structure as an organic entity, i.e. the inclusion of all the preceding indicators into an encompassing index. The proposed index will then reflect on a city's vitality. Vitality describes the ability of an organism to stay alive or work effectively. The Vitality Index ${ }^{\odot}$ will encompass indicators that represent the ability of an urban centre to stay alive, be viable, and function satisfactorily in order to provide for the basic needs of the community and improve the lives of all residents in the long term.

\section{Urban indicators: an integrated perspective}

In the mid 1960s a growing dissatisfaction with the availability of quality social information prompted the "social indicators movement" (Carley [4]). This was due to the growing concern of too much attention being directed to economic performance and indicators. The term social indicators encompassed a wide variety of indicators of socio-economic well-being and quality of life.

Social indicators can be divided into a number of broad classifications (Carley [4]), of which the distinction between objective and subjective indicators is probably the most widely used. According to Land [5] social indicators can be further divided into normative welfare indicators, satisfaction indicators, and descriptive social indicators. Normative welfare indicators closely correlate to objective indicators since they refer to direct measures of welfare, i.e. income. Descriptive indicators are an encompassing index of a number of indicators which measure social conditions within an urban centre or urban centres. 


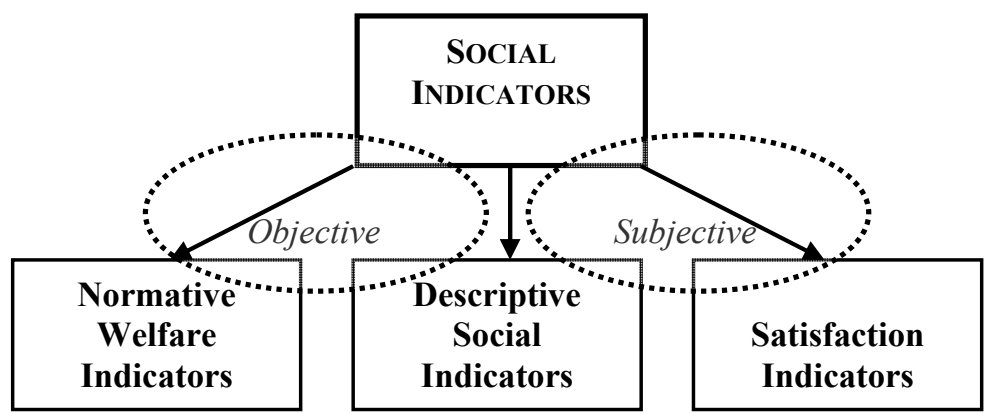

Figure 1: $\quad$ Types of social indicators (own representation).

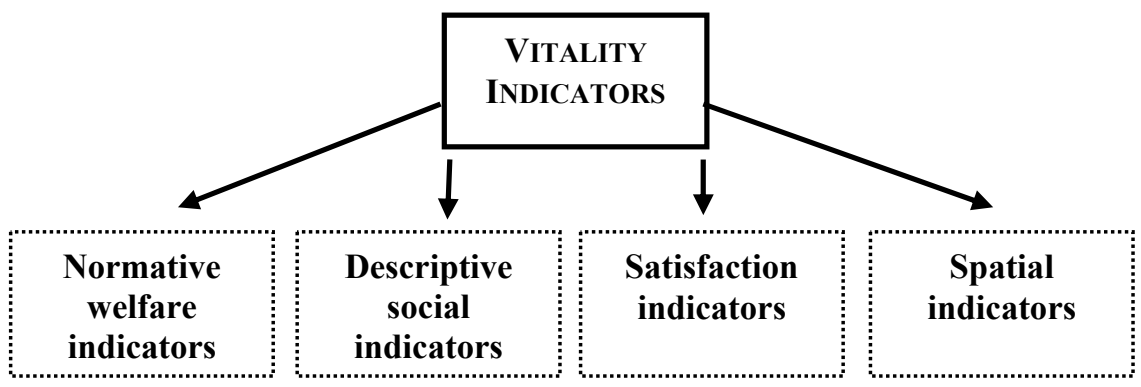

Figure 2: $\quad$ Subgroups of Vitality Indicators.

\section{Subgroups of indicators}

The aforementioned groupings of indicators will form part of the four subgroups in the Vitality Index ${ }^{\mathscr{C}}$. The remaining indicators that do not fall in the scope of one of these subgroups are mainly measures of spatial importance, and will hence be categorised under a fourth subgroup, i.e. spatial indicators (Land [5]).

This study will attempt to identify and create a comprehensive index. Only the indicators of highest value and importance will be highlighted and included in the index. A number of indicators were identified to be part of the final Vitality Index ${ }^{\mathcal{O}}$, taking into account the availability of data and relative importance of the indicator.

\subsection{Normative welfare indicators}

Normative welfare indicators are objective indicators which act as direct measures of welfare within a community or region (Land [5]). The first indicator of normative welfare refers to the basic-nonbasic relationship, which describes the relationship between services and products provided for the local community (nonbasic), and services and products exported to the surrounding region (basic) (Alexander [6]). The presence of a large export base (basic sector) may indicate future economic growth and development (Alexander [6]). The larger the export 
base, the more revenue is collected from outside the urban centre. Money is consequently not only circulated within the community, as with non-basic services, but money is added to the local economy.

The second indicator that may be categorised as a normative welfare indicator is the GDP. In the past, public policy-makers generally relied on the GDP as a primary measure of a nation's well-being (Van der Merwe et al. [7]). Although numerous criticisms were levelled at the GDP, it can still play a role in measuring economic activity within a region or urban centre and data are fairly readily available for the whole of South Africa (RSA [8]). In the third place, the income of a community may be categorised as a normative welfare indicator. The income of a community is representative of its ability to satisfy its basic needs (DBSA [1]). This indicator correlates to the employment level and GDP of a community.

\subsection{Satisfaction indicators}

In this subgroup two indicators are most prominent as representative of life satisfaction. First, a person's perception of the environment may be said to be indicative of his satisfaction in general. Secondly, the concept of Quality of Life (QOL) attempts to quantify a number of general indicators to reflect a community's general feeling of well-being and satisfaction. This index comprises numerous variables such as material well-being, health, political stability and security, family life; community life; climate and geography, job security, political freedom and education. These indicators are not so much indicators of growth and development, as they are measures of the impact of growth and development (Venetoulis and Talberth [9]).

\subsection{Descriptive social indicators}

The subgroup of descriptive social indicators takes into account a large number of indicators, including physical, demographic, institutional and labour indicators. Land [5] described this subgroup as an encompassing index of indicators of social conditions and changes therein over a period of time for various sectors of the population. These indicators are all based on objective quantitative data and are, therefore, fairly readily available and easy to interpret. The physical indicators are infrastructure and transport. Infrastructure is measured according to the availability of engineering and basic services.

The second group of descriptive social indicators is the demography of a region or town. Demography includes indicators such as population, population growth rate, age and gender distribution, level of education and life expectancy. In the third instance, labour and employment can also be classified as a descriptive social indicator. The final descriptive social indicator that is proposed to be included in this subgroup is that of institutional capacity. This indicator refers to the capacity of local government to provide basic services to the community as well as the capacity to manage the urban centre in question as efficiently as possible. 


\subsection{Spatial indicators}

This study is focussed on the field of regional planning, and the spatial aspects of performance and growth should therefore play a central role in the Vitality Index ${ }^{\circ}$. Spatial indicators have not been proposed by any of the authors or researchers on indicators or social indicators. Most of the indicators researched during this study provide for a comparison of urban centres, but not for the classification of centres in terms of regional importance.

It is proposed that the following spatial concepts be included as spatial indicators, i.e. (i) the reason for the town's continued existence; (ii) the position of the town within the urban system; (iii) the hierarchical position of the town in the region; (iv) the presence of development corridors in the region; and (v) existing policy initiatives as proposed by national, provincial and district governments.

The first measure of spatial importance to be included is the central place system and town's relative importance in the region based on the centrality of the town and the services it provides to the surrounding region. Boudeville [10] described a regional growth pole as a number of growing industries situated in an urban area and stimulating further development of economic activity throughout its sphere of influence. The growth-pole concept is thus regarded as an important indicator of future spatial growth and performance in a regional context.

The position of an urban centre in the hierarchical distribution of is also indicative of the relative importance of the specific centre in the region. A town's hierarchy can be linked to its urban field, whereas the size of the urban field of a town will be directly proportional to its hierarchical order. The levels of relations in the urban system will differ in scale and composition at different levels of urban hierarchy (Berry and Horton [11]; Bourne [12]).

Another spatial indicator is the existence and relative location of development corridors since development corridors stimulate growth and development in nodes (Richardson [13]). It is proposed that existing policy initiatives also be included as a Spatial Indicator. Urban centres mentioned in spatial policy documents on National, Provincial and District level are regarded as centres of potential growth, and therefore receive additional incentives to encourage growth.

\section{Empirical study}

The proposed study area used to test the Vitality Index ${ }^{\odot}$ is situated in the Northern Cape Province, South Africa. The Northern Cape Province is sparsely populated and has very few large urban centres occurring at irregular intervals and has a fairly homogeneous geography. The homogeneous plain (Dicken and Lloyd [14]) is also highlighted by theorists of simplified settlement theories as a way of simplifying the complexity of space economy.

Research in South Africa is mostly focused on the metropolitan areas and larger urban centres in the country (SACN [15]). Unlike many other provinces, the Northern Cape has not been the subject of many research studies. This study 
will therefore attempt to make a contribution to undertake research in an area of the country which has not been researched extensively. The study will concentrate on urban centres within the two District Municipalities, in question, which include the following Local Municipalities and centres:

a) Frances Baard DM (Sol Plaatjie LM: Kimberley; Dikgatlong LM: Barkley West, Delportshoop, Windsorton; Magareng LM: Warrenton; Phokwane LM: Jan Kempdorp, Pampierstat, Hartswater), and

b) Kgalagadi DM (Moshaweng LM: Heuningvlei, Tsineng, Bothithong; GaSegonyana LM: Kuruman, Mothibistad; Gamagara LM: Deben, Kathu, Dingleton, Olifantshoek)

These two district municipalities are adjacent to each other and have specifically been selected since they include a large number of urban centres of different hierarchical levels in the national, regional, and daily urban systems. The study area furthermore fits into the core-periphery model, with certain centres forming part of the core, while other centres and development corridors are included in the transition zone, and the periphery (Friedmann [16]). Due to the extent of the Northern Cape it is sparsely populated, with few national roads (i.e. N8 and N12) passing through. The latter is important due to the importance of a development corridor and the influence it has on the urban centres close by. Since the Northern Cape is such a large province with numerous smaller settlements, the infrastructure is mostly insufficient in smaller towns. This will enable the study to determine the importance of infrastructure as an indicator of vitality.

This study will relate all data back to the largest town within each local municipality, as identified according to the size of population. This is as a result

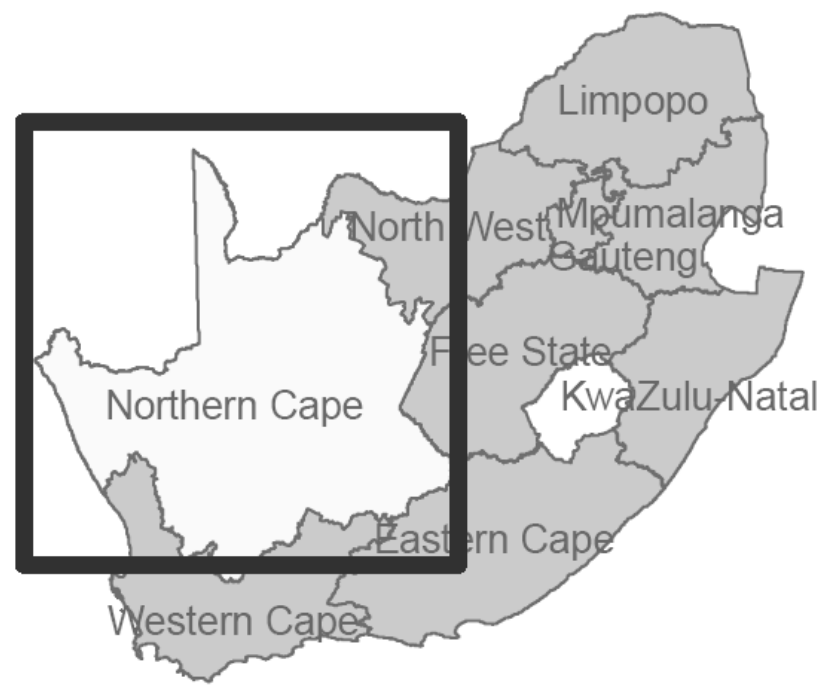

Figure 3: $\quad$ Study area - Northern Cape Province, South Africa. 
of the Local Municipality's political importance, and spatial initiatives which are mainly focused on main urban centres in terms of SDF's (Spatial Development Framework) and IDP's (Integrated Development Plan). The NSDP [17] proposes to focus upon localities that demonstrate some economic potential and high levels of social need, since greater benefits will be achieved by focussing resources and effort on these localities.

\section{Vitality indicators}

The Vitality Index ${ }^{(}$comprises each of the aforementioned subcategories, i.e. normative welfare, satisfaction, descriptive social and spatial indicators. The Vitality Index ${ }^{\mathcal{O}}$ will be determined for each municipality by adding all the scores for each subcategory, i.e.

$$
\begin{aligned}
\text { Vitality Index }= & (1 / 4) \text { Normative welfare indicator score } \\
& +(1 / 4) \text { Satisfaction indicator score } \\
& +(1 / 4) \text { Descriptive social indicator score } \\
& +(1 / 4) \text { Spatial indicator score }
\end{aligned}
$$

The Vitality Index $^{\odot}$ is consequently determined by making use of the scores obtained in each of the four subcategories. Each subcategory consists of $n$ indicators, each of which is individually scored in terms of the proposed quartile system. The scores for the indicators are added up to constitute a total score out of a possible total of $\left(n^{*} 4\right)$ - a maximum score of four per indicator can be obtained. A percentage value for the subcategory is calculated.

The subcategory could obtain a score (from one to four) based on the quartile system or the percentage values could be used. The Vitality $\left.\operatorname{Index}^{(}\right)$is calculated as the total of the percentage value of each of the subcategories (thus resulting in a total out of four hundred). The Vitality Index ${ }^{(}$can be presented in three ways, as illustrated in the subsequent table. Firstly, the percentage values for each subcategory could be added up and converted to a percentage, namely the Vitality Percentage. On the basis of this vitality percentage, each of the urban centres can be scored in terms of the proposed quartile system, obtaining a Vitality Score of between one and four. The vitality percentage could also be used to rank the urban centres in the specific region; viz. the centre with the highest percentage will receive the highest ranking (subject to the number of urban centres in the study area) resulting in the Vitality Ranking.

To determine a broad classification of urban centres one will make use of the vitality score, whereas a more in-depth study of urban centres will call for the vitality percentage to be utilised. The Vitality Ranking could be used in order to give a brief overview of the vitality position of each urban centre within the broader region. The table below illustrates the final Vitality Index ${ }^{\complement}$ Score, as proposed by this study, for each municipality.

This table suggests that Kimberley (Sol Plaatjie Municipality) is the urban centre with the highest vitality. Kathu (Gamagara Municipality) surprisingly 


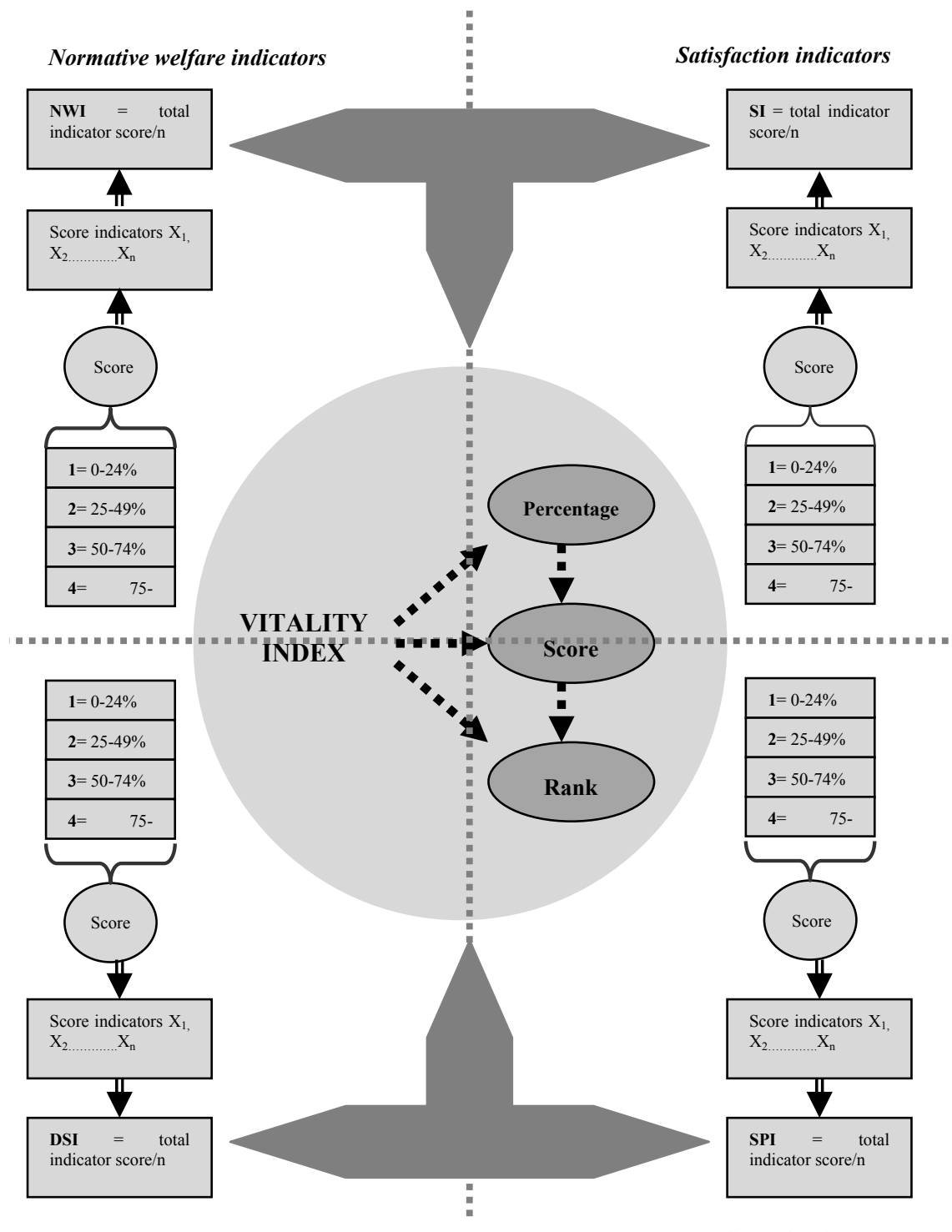

Descriptive social indicators

Spatial indicators

Figure 4: $\quad$ Methodology of Vitality Index ${ }^{(}$.

illustrates the second highest vitality percentage with $66,39 \%$, which could be ascribed to the mining activities and rapid economic growth within the mining sector. Kathu (Gamagara Municipality) is followed by Kuruman (Ga-Segonyana Municipality), Jan Kempdorp (Phokwane Municipality), and Barkley West (Dikgatlong Municipality), each of which obtained a vitality score of three. 
Table 1: $\quad$ Vitality Index ${ }^{\mathcal{O}}$ scores.

\begin{tabular}{|l|c|c|c|c|c|c|c|}
\hline Indicator & Ga-Segonyana & Gamagara & Moshaweng & Phokwane & Sol Plaatjie & Dikgatlong & Magareng \\
\hline $\begin{array}{l}\text { Normative } \\
\text { welfare } \\
\text { indicator score }\end{array}$ & 2 & 4 & 3 & 3 & 3 & 3 & 1 \\
\hline $\begin{array}{l}\text { Satisfaction } \\
\text { indicator score }\end{array}$ & 3 & 3 & 3 & 3 & 3 & 3 & 3 \\
\hline $\begin{array}{l}\text { Descriptive } \\
\text { social indicator } \\
\text { score }\end{array}$ & 3 & 3 & 2 & 3 & 4 & 3 & 3 \\
\hline $\begin{array}{l}\text { Spatial } \\
\text { indicator score }\end{array}$ & 4 & 4 & 2 & 2 & 4 & 2 & 2 \\
\hline $\begin{array}{l}\text { Vitality Index } \\
\text { \% }\end{array}$ & $\mathbf{6 3 . 8 9}$ & $\mathbf{6 6 . 3 9}$ & $\mathbf{4 8 . 5 4}$ & $\mathbf{5 6 . 6 0}$ & $\mathbf{7 7 . 7 1}$ & $\mathbf{5 3 . 7 5}$ & $\mathbf{4 1 . 6 0}$ \\
\hline $\begin{array}{l}\text { Vitality Index } \\
\text { Score }\end{array}$ & $\mathbf{3}$ & $\mathbf{3}$ & $\mathbf{2}$ & $\mathbf{3}$ & $\mathbf{4}$ & $\mathbf{3}$ & $\mathbf{2}$ \\
\hline $\begin{array}{l}\text { Vitality Index } \\
\text { rank }\end{array}$ & $\mathbf{5}$ & $\mathbf{6}$ & $\mathbf{2}$ & $\mathbf{4}$ & $\mathbf{7}$ & $\mathbf{3}$ & $\mathbf{1}$ \\
\hline
\end{tabular}

These towns thus show the ability to perform their tasks effectively and to provide for the needs of their residents. Bothithong (Moshaweng Municipality) and Warrenton (Magareng Municipality) on the other hand have low levels of vitality with a score of two each and are thus ranked low with regard to spatial importance within the study area as a whole.

The table also allows for a more detailed interurban evaluation of the subcategories. It should be noted that the gap between the highest and second highest rank is more than ten percent - Kimberley thus excels as a definite core centre within the study area. It is therefore possible to use the Vitality Index ${ }^{\circ}$ on two different levels, whether for a broad categorisation or for a detailed ranking, in accordance with the needs of a study.

\section{Synthesis and recommendations}

This study is focused on the spatial importance of urban centres within a larger study area or region. It is important that each of the indicators discussed be related back to what it measures. The indicators are related back to the immeasurable concept, i.e. spatial importance, for which it is a substitute. The purpose of the Vitality Index ${ }^{\mathcal{O}}$ was to serve as a comprehensive index measuring the importance of an urban centre within a larger region.

It is also possible to apply the Vitality Index ${ }^{\mathcal{O}}$ to different study areas throughout the world. The Vitality Index ${ }^{\mathcal{O}}$ also allows for additional indicators to be included in the subcategories identified. Indicators could subsequently also be discarded if deemed unnecessary for the specific goal or region in mind.

This study identified a limitation with regard to existing indicators and therefore the spatial aspects of urban centres should also be considered when a region is measured. Furthermore, this study confirmed the fact that qualitative 
indicators were ignored in existing methods of urban centre measurement. As urban centres exist and function within a larger region all urban centres are interrelated, this study proposed the utilisation of a comprehensive index to measure the importance of an urban centre within a specific region.

This study contributed in a number of ways to the measurement of urban centres, including the classification of urban indicators into four broad categories, i.e. normative welfare, satisfaction, descriptive social and spatial indicators. Different methods were proposed for calculating the Vitality Index ${ }^{\circledR}$, including the ranking and scoring of urban centres. This made it possible to determine the ability of an urban centre to function satisfactorily over time and to stay vibrant and viable. It was proposed that shortcomings that were identified for the urban centre be addressed by policy initiatives, comprising a set of objectives and strategies to correct imbalances. The Vitality Index ${ }^{\odot}$ also provides a basis for informing national and provincial growth policies, in the identification of urban centres with sustainable growth potential and vitality.

\section{References}

[1] DBSA. Guidelines to regional socio-economic analysis. DBSA: Johannesburg. 54p. 2001.

[2] Schneider, M. 1976. The quality of life and social indicators. Public Administration Review, 1: 297-395. 1976.

[3] Liu, B. Quality of life: concept, measure and results. The American Journal of Economics and Sociology (34)1: 1-12. 1975.

[4] Carley, M. Social measurement and social indicators. George Allen \& Unwin: London. 195p. 1981.

[5] Land, K.C. Social Indicators. Annual review of Sociology, 9: 1-26. 1983.

[6] Alexander, J.W. The basic-nonbasic concept of urban economic functions. Economic geography, 30: 246-261. 1954.

[7] Van der Merwe, C., Mohr, P.J., Botha, Z.C. \& Inggs, E.J. The practical guide to South African economic indicators. Lexicon Publishers: Johannesburg. 146p. 1988.

[8] RSA Regional Market Indicators. [Web:] http://regions.easydata.co.za [Date of use: 23 Oct. 2006]. 2001.

[9] Venetoulis, J. \& Talberth, J. Ecological footprint of nations - 2005 update. Redefining Progress, 1-16. 2005.

[10] Boudeville, J.R. Problems of regional economic planning. University press: Edinburgh. 192p. 1966.

[11] Berry, B.J.L \& Horton, F.E. Geographic perspectives on urban systems with integrated readings. Prentice-Hall: New Jersey. 564p. 1970.

[12] Bourne, L.S. Urban systems: strategies for regulation. Clarendon Press: Oxford. 264p. 1975.

[13] Richardson, H.W. Spatial strategies, the settlement pattern and shelter and services policies. (In Rodwin, L. ed. Shelter, settlement and development. Boston: Allen. P.207-235.) 1987. 
[14] Dicken, P. \& Lloyd, P.E. Location in space: Theoretical perspectives in economic geography ( ${ }^{\text {rd }}$ ed.). HarperCollins: New York. 431p. 1990.

[15] South African Cities Network. [Web:] http://sacities.net [Date of use: 10 Nov. 2006]. 2006.

[16] Friedmann, J. Regional Development Policy: A case study of Venezuela. M.I.T. Press: Massachusetts. 273p. 1966.

[17] South Africa. National Spatial Development Perspective. Government Printer: Pretoria. 43p. 2003. 